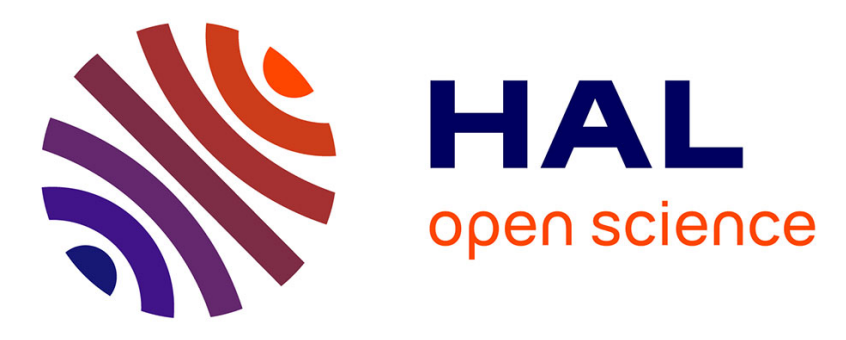

\title{
Synthesis of new flame-retardants by radical chain transfer copolymerization of glycidyl methacrylate and dimethoxy-phosphorylmethyl methacrylate
}

Raphaël Menard, Claire Negrell-Guirao, Laurent Ferry, Rodolphe Sonnier, Ghislain David

\section{To cite this version:}

Raphaël Menard, Claire Negrell-Guirao, Laurent Ferry, Rodolphe Sonnier, Ghislain David. Synthesis of new flame-retardants by radical chain transfer copolymerization of glycidyl methacrylate and dimethoxy-phosphorylmethyl methacrylate. European Polymer Journal, 2014, 57, pp.109-120. 10.1016/j.eurpolymj.2014.05.006 . hal-01010440

\author{
HAL Id: hal-01010440 \\ https://hal.science/hal-01010440
}

Submitted on 27 Jun 2014

HAL is a multi-disciplinary open access archive for the deposit and dissemination of scientific research documents, whether they are published or not. The documents may come from teaching and research institutions in France or abroad, or from public or private research centers.
L'archive ouverte pluridisciplinaire HAL, est destinée au dépôt et à la diffusion de documents scientifiques de niveau recherche, publiés ou non, émanant des établissements d'enseignement et de recherche français ou étrangers, des laboratoires publics ou privés. 


\title{
Synthesis of new flame-retardants by radical chain transfer copolymerization of Glycidyl Methacrylate and Dimethoxy-phosphorylmethyl Methacrylate.
}

\author{
Raphaël Ménard ${ }^{\mathrm{a}, \mathrm{b}}$, Claire Negrell-Guirao ${ }^{\mathrm{a} *}$, Laurent Ferry $^{\mathrm{b}}$, Rodolphe Sonnier ${ }^{\mathrm{b}}$ and Ghislain David ${ }^{\mathrm{a}}$
}

${ }^{a}$ Institut Charles Gerhardt, Montpellier, UMR CNRS 5253, Equipe Ingénierie et Architectures Macromoléculaires, Ecole Nationale Supérieure de Chimie de Montpellier, 8 rue de l'école normale, 34296 Montpellier Cedex 5, France. *Email Address: claire.negrell@enscm.fr

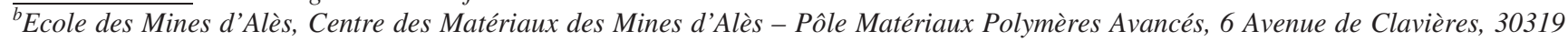
Ales Cedex, France

\begin{abstract}
We present a new and original approach to prepare flame retardants (FR) compounds. The strategy adopted consists first in synthesizing new reactive phosphorus-containing oligomers and then to chemically graft them to an epoxy network. These reactive FR compounds are synthesized by radical chain transfer copolymerization of dimethoxy-phosphorylmethyl methacrylate (MAPC1) with glycidyl methacrylate (MAGLY). Reactivity ratios were determined $\mathrm{r}_{\mathrm{MAPC} 1}=0.78$ and $\mathrm{r}_{\mathrm{MAGLY}}=1.28$ at $80^{\circ} \mathrm{C}$. The molecular weight of all the (co)oligomers was calculated by steric exclusion chromatography between 1000 to 3000 g.mol ${ }^{-1}$. The synthesized FR were incorporated into an epoxy matrix as reactive binders. Then these formulations were cured at high temperature and the cross-linking densities were determined by DSC. The thermal properties and burning behaviors of cured epoxy resins were investigated. Thermogravimetric analysis showed a small decrease in thermal stability accompanied by a $50 \%$ increase in char yield. Pyrolysis combustion flow calorimetry (PCFC) was also used to evaluate the flammability of the modified epoxy resin. A significant decrease in peak of heat release rate (pHRR) and total heat release (THR) was observed. Indeed, with $3 \%_{\mathrm{w}} \mathrm{P}$, the THR was reduced by $25 \%$ and the maximal heat release rate by $60 \%$ compared to the reference. These results demonstrate the good flame retardant properties of reactive oligomers in epoxy matrix.
\end{abstract}

Keywords: Chain Transfer Reaction, Phosphorus Oligomer, Reactive Flame Retardant and Epoxy Network.

\section{Introduction}

Epoxy resins are an important part of the thermosets market. They are widely used for their characteristics, such as excellent mechanical properties, adhesion or thermal resistance and have many 
applications in adhesives industry, coatings, and electronic components. Epoxy resins in combination with fibers are also used as a matrix to form composites used in sports and aeronautic industries. In order to expand their applications and to respect new standards, it is required to adjust their properties by introducing additives. Thus, plasticizers, compatibilizers, crosslinking agents or fillers can be used to tailor mechanical, adhesion or rheological properties. Flammability is directly dependent on the chemical structure of the polymeric matrix and can be modified by adding flame retardants. Phosphorus compounds are currently the most studied FR because of use restrictions of halogenated products imposed by REACH or RoHS regulations ${ }^{[1] ~[2]}$. They can act in condensed phase and/or gas phase where they release low toxic compounds ${ }^{[3]}{ }^{[4]}$. The modes of action of phosphorus FR depends on their molecular weight and oxidation state of the phosphorus atoms ${ }^{[5]}$. For these reasons, our study will be conducted on phosphorus compounds. Flame retardancy can be reached according to two approaches. The first one is the additive approach which consists of physically incorporating an additive in the material during its implementation. The main drawback of this approach is the mobility of the FR in the matrix. This mobility could induce migration of the FR, resulting in leaching and heterogeneous FR concentration in the material resulting in nonpermanent flame retardancy. The release of the additive in the gas phase can also be expected during thermal degradation, and thus the charring effect is reduced. Finally, such a leaching leads to health and environmental risks ${ }^{[6]}$.

To ensure a permanent thermal behavior, FR migration has to be reduced. Wang et al. ${ }^{[7]}$ showed by mathematic modeling that compounds migration is inversely proportional to their molecular weight. An increase in the molar weight leads to a reduced mobility in the material and a better action in condensed phase ${ }^{[8]}{ }^{[9]}$. Hence, FR oligomers synthesized by radical polymerization of halogenated styrene monomers are commercially available and used in some epoxy resins ${ }^{[10]}$. Mobility of FR is also dependent on its interactions with the matrix. Oligomers incorporation could be problematic in the case of poor compatibility between oligomers and matrix. Phase segregation can occur and can be detrimental to the properties of the prepared material.

FR mobility can also be reduced by a second approach (called reactive approach) which consists in creating covalent bonds between matrix and FR. The reactive approach promotes an action in the condensed phase and the formation of a high temperature stable residue. Many studies pointed out the phosphorus FR efficiency in epoxy matrices. Different approaches have been reported. Lligadas et al. ${ }^{[11]}$ have synthesized a derivative form of 9,10-dihydro-9-oxa-phosphaphenanthrene-10-oxide (DOPO) with reactive epoxy which has good reactivity 
with various aromatic diamines. Ren et al. ${ }^{[12]}$ have also shown the efficiency of the reactive approach through the synthesis and the curing of diepoxy phosphonate compounds. This study also demonstrated the better efficiency in condensed phase of reactive phosphonate compared to reactive halogenated compounds. Schartel et al. ${ }^{[13]}$ have shown the flame retardant action of phosphorylated diamines used as curing agent. All these studies reported an important charring effect during thermal decomposition when a phosphorylated compound is used as matrix or curing agent.

The purpose of the present study is to combine both the above-described approaches to limit the FR mobility and migration in the matrix through the synthesis of reactive phosphorylated oligomers and their chemical incorporation in epoxy resin. This strategy consists in copolymerizing two methacrylic monomers by radical chain transfer polymerization. The two chosen monomers are dimethoxy-phosphorylmethyl methacrylate (MAPC1) and glycidyl methacrylate (MAGLY) for its oxirane reactive ring. Radical copolymerization of these two monomers with methyl methacrylate (MMA) has already been studied but no paper has reported the synthesis of MAPC1/MAGLY copolymers so far.

Neugebauer et al. ${ }^{[14]}$ reported the radical copolymerization of MMA with MAGLY by atom transfer radical copolymerization. The statistical structure was deduced from reactivity ratios $\left(\mathrm{r}_{\mathrm{MAGLY}}=1.24, \mathrm{r}_{\mathrm{MMA}}=0.85\right.$ at $80^{\circ} \mathrm{C}$ ). Iwakura et al. ${ }^{[15]}$ carried out the synthesis of a MAGLY/MMA copolymers by conventional radical copolymerization and the reactivity ratios also confirmed a statistical structure. The chains formed had good reactivity with secondary amine due to the epoxy functions. Finally, an-other study carried out by Gluckman et al. ${ }^{[16]}$ confirmed the statistical structure from reactivity ratios $\left(\mathrm{r}_{\mathrm{MAGLY}}=1.05, \mathrm{r}_{\mathrm{MMA}}=0.80\right.$ at $\left.80^{\circ} \mathrm{C}\right)$. El-Asri et al. ${ }^{[17]}$ studied the synthesis of the phosphonated methacrylic monomer (MAPC1) and its radical copolymerization with MMA. Results showed close reactivity ratios $\left(\mathrm{r}_{\mathrm{MAPCl}}=1.08, \mathrm{r}_{\mathrm{MMA}}=1.00\right)$ enabling to assume a statistical structure. Thus, according to the literature, the radical copolymerization of MAGLY with MAPC1 should result in statistical copolymers, which would favor a homogeneous repartition of both epoxy and phosphonate groups along the backbone.

In this article, the synthesis of MAGLY/MAPC1 copolymer by radical chain transfer polymerization (RCTP) in the presence of mercaptoethanol as chain transfer agent is reported. RCTP allows a low degree of polymerization $\left(\mathrm{DP}_{\mathrm{n}}\right)$ of the produced chains. Thiol based chain transfer agent $(\mathrm{CTA})$ is suitable for methacrylic 
monomers copolymerization, since it exhibits a transfer constant close to 1 with methacrylic monomers. Hence $\mathrm{DP}_{\mathrm{n}}$ is limited by the $[\text { thiol }]_{0} /[\text { monomers }]_{0}$ ratio. In this study, targeted $\mathrm{DP}_{\mathrm{n}}$ was targeted to 15 monomers units to obtain molar weights around $3000 \mathrm{~g} / \mathrm{mol}$. Oligomeric chains were then introduced in different amounts in epoxy matrix and a comparative study of material behaviors was carried out by thermogravimetric and PCFC analyses.

\section{Experimental part}

\section{Materials}

Glycidyl methacrylate, 2-mercaptoethanol, diethylether, acetonitrile, diglycidyl ether of bisphenol A (DGEBA) resin and curing agent isophorone diamine (IPDA) were purchased from Sigma-Aldrich. 2,2azobisisobutyronitrile (AIBN) was purchased from Sigma-Aldrich and have been purified by recrystallization in methanol (10g/200ml). Dimethoxy-phosphorylmethyl methacrylate (MAPC1) was purchased from Specific Polymers.

\section{Synthesis of copolymers}

The following experimental conditions enabled to optimize the monomer conversions.

The comonomer mixture $(0.20 \mathrm{~mol}$, used ratios are detailed in table 1) was transferred with $20 \mathrm{~mL}$ of acetonitrile in a $100 \mathrm{~mL}$ two-necked round-bottomed flask equipped with a stirrer, a rubber septum and a condenser connected to a high purity nitrogen source. After degassing for 20 minutes, $1.54 \mathrm{~g}$ (0.02 mol) of 2mercaptoethanol was added using a syringe through the septum. The solution was heated at $80{ }^{\circ} \mathrm{C}$ under vigorous stirring. Finally, $33 \mathrm{mg}(0.2 \mathrm{mmol})$ of AIBN was dissolved in $10 \mathrm{~mL}$ of acetonitrile and added in three equal additions at $t_{0}, t_{0}+4 h$ et $t_{0}+8 h$. At $t_{0}+24 h$, the system was purified by dropwise precipitation in $300 \mathrm{~mL}$ of frozen diethyl ether under stirring. Obtained oligomers were dried at room temperature under vacuum and ground to form a white powder. Cotelomers were characterized by ${ }^{31} \mathrm{P}-\mathrm{NMR}$ and ${ }^{1} \mathrm{H}-\mathrm{NMR}$ in order to verify purity.

Three cotelomers and two telomers were synthesized from the above method. Table 1 displays the initial monomer amounts. Synthesized oligomers have been named according to their theoretical MAGLY/MAPC1 ratios. 


\begin{tabular}{|c|c|c|c|c|c|}
\hline Oligomers & $\begin{array}{c}\text { MAGLY/MAPC1 } \\
\text { molar ratio }\end{array}$ & $\begin{array}{c}\mathrm{m} \\
\text { MAGLY } \\
(\mathrm{g})\end{array}$ & $\begin{array}{c}\mathrm{n} \\
\text { MAGLY } \\
(\mathrm{mole})\end{array}$ & $\begin{array}{c}\mathrm{m} \\
\text { MAPC1 } \\
(\mathrm{g})\end{array}$ & $\begin{array}{c}\mathrm{n} \\
\text { MAPC1 } \\
(\mathrm{mole})\end{array}$ \\
\hline $20 E P 80 P$ & $20 / 80$ & 5.68 & 0.04 & 28.32 & 0.16 \\
\hline $50 E P 50 P$ & $50 / 50$ & 14.20 & 0.10 & 17.70 & 0.10 \\
\hline $70 E P 30 P$ & $70 / 30$ & 19.88 & 0.14 & 10.62 & 0.06 \\
\hline $100 E P$ & $100 / 0$ & 28.40 & 0.20 & 0 & 0 \\
\hline $100 P$ & $0 / 100$ & 0 & 0 & 35.40 & 0.20 \\
\hline
\end{tabular}

Table 1: Amounts of monomers introduced in radical copolymerization of MAPC1 and MAGLY

20EP80P (Figure 1): ${ }^{1} \mathrm{H}_{\mathrm{NMR}}\left(400 \mathrm{MHz}_{2} \delta\right.$ ) $: 4.25\left[2 \mathrm{H}, \mathrm{C}(\mathrm{O})-\mathrm{O}_{-} \mathrm{CH}_{2}\right] ; 3.82$ and $3.71\left[6 \mathrm{H}, \mathrm{P}-\mathrm{O}-\mathrm{CH}{ }_{3}\right.$ and $\left.1 \mathrm{H}, \mathrm{C}(\mathrm{O})-\mathrm{OCH}_{2}\right] ; 3.63\left[2 \mathrm{H}, \mathrm{CH}_{2}-\mathrm{OH}\right] ; 3.22[1 \mathrm{H},-\mathrm{CH}-\mathrm{Ox}] ; 2.85\left[1 \mathrm{H}, \mathrm{CH}_{2}-\mathrm{Ox}\right] ; 2.65\left[1 \mathrm{H}, \mathrm{CH} \mathbf{H}_{2}-\mathrm{Ox}\right]$ and

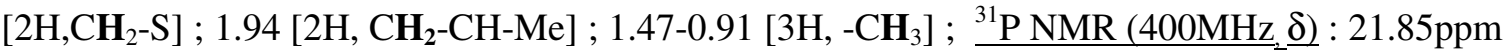

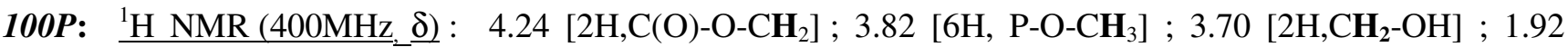
$\left[2 \mathrm{H}, \mathrm{CH}_{2}-\mathrm{CH}-\mathrm{Me}\right] ; 1.09$ and $0.91\left[3 \mathrm{H},-\mathrm{CH}_{3}\right] ;{ }^{31} \mathrm{P} \mathrm{NMR}\left(400 \mathrm{MHz}_{2} \underline{\delta}\right): 21.85 \mathrm{ppm}$

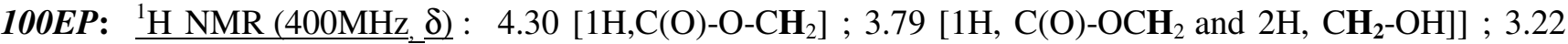
[-CH-Ox] ; $2.83\left[\mathrm{CH}_{2}-\mathrm{Ox}\right] ; 2.62\left[\mathrm{CH}_{2}-\mathrm{Ox}\right] ; 1.96\left[\mathrm{CH}_{2}-\mathrm{CH}-\mathrm{Me}\right] ; 1.08$ and $0.92\left[-\mathrm{CH}_{3}\right]$

To determine the reactivity ratio of each monomer, a kinetic was carried out for the 20EP80P synthesis. Samples were collected every 10 minutes for 1.5 hours. Monomer conversion is determined by ${ }^{1} \mathrm{H}-\mathrm{NMR}$ spectroscopy.

\section{Materials preparation}

Different materials were prepared in order to evaluate the influence of both phosphorus ratio and oligomer contents on the flame retardancy.

Table 2 summarizes data for material preparation. The oligomer was solubilized in DGEBA under stirring at $120{ }^{\circ} \mathrm{C}$ for $1 \mathrm{~h}$. The mixture was cooled at $50^{\circ} \mathrm{C}$ to avoid any crosslinking upon mixing with the hardener. With respect to the epoxy/amine ratio (2/1), adequate amount of IPDA was then added to the mixture at $50{ }^{\circ} \mathrm{C}$. The system was stirred manually for 5 minutes. Finally, the mixture was crosslinked in a circular rubber mold according to the following temperature program: $4 \mathrm{~h}$ at $80^{\circ} \mathrm{C}$ and $10 \mathrm{~h}$ at $150^{\circ} \mathrm{C}$. Materials are named according 
to their phosphorus content followed by the used oligomer: "x\% $\mathrm{P}$ (used oligomer)". The reference material is the stoichiometric DGEBA/IPDA (2/1) system.

\begin{tabular}{|c|c|c|c|}
\hline Materials & $\begin{array}{c}\text { Weight composition }\left(\%_{\mathrm{w}}\right) \\
\text { (DGEBA/IPDA/FR) }\end{array}$ & $\begin{array}{c}\text { Used } \\
\text { oligomer as } \\
\text { FR }\end{array}$ & $\begin{array}{l}\text { Phosphorus } \\
\text { content }\left(\%_{w} \mathbf{P}\right)\end{array}$ \\
\hline reference & $80 / 20 / 0$ & $\mathbf{X}$ & $\mathbf{0}$ \\
\hline $0 \% P(100 E P)$ & 73.6/19.4/7.0 & 100EP & $\mathbf{0}$ \\
\hline $0.8 \% P(70 E P 30 P)$ & 67.1/19.2/13.7 & 70EP30P & 0.81 \\
\hline $0.9 \% P(50 E P 50 P)$ & 71.3/18.5/10.2 & 50EP50P & 0.91 \\
\hline $1 \% P(20 E P 80 P)$ & 74.1/18.7/7.2 & 20EP80P & 1.00 \\
\hline $0.9 \% P(70 E P 30 P)$ & 65.9/19.1/15.0 & 70EP30P & 0.90 \\
\hline $1.35 \% P(50 E P 50 P)$ & $66.4 / 18.6 / 15.0$ & 50EP50P & 1.35 \\
\hline $2.1 \% P(20 E P 80 P)$ & 67.4/17.6/15.0 & 20EP80P & 2.10 \\
\hline $3 \% P(20 E P 80 P)$ & 61.7/17.0/21.3 & 20EP80P & 3.00 \\
\hline $3 \% P(100 P)$ & 66.3/16.6/17.1 & 100P & 3.00 \\
\hline
\end{tabular}

Table 2: Compositions of the formulated epoxy materials

\section{Characterizations}

Chemical structure of the oligomers was determined by ${ }^{31} \mathrm{P}$ - and ${ }^{1} \mathrm{H}-\mathrm{NMR}$ spectroscopy in a Bruker Avance $400 \mathrm{MHz}$ spectrometer at room temperature in $\mathrm{CDCl}_{3}$ solutions. External references are trimethylsilane (TMS) for ${ }^{1} \mathrm{H}-\mathrm{NMR}$ and phosphoric acid $\left(\mathrm{H}_{3} \mathrm{PO}_{4}\right)$ for ${ }^{31} \mathrm{P}-\mathrm{NMR}$. Shifts are given in ppm.

Steric exclusion chromatography analyses were carried out with a Varian PL-GPC-50 chromatograph equipped with a RI detector. Two PL GeL Mixed-C columns thermostated at $35^{\circ} \mathrm{C}$ were used with an eluent flow of 1 $\mathrm{ml} / \mathrm{min}$. Columns were calibrated with polymethylmethacrylate (PMMA) standards. Size exclusion chromatography (SEC) analyses are performed on purified oligomers in tetrahydrofuran (THF) with a small amount of toluene as flow rate marker.

Thermal analyses were performed using samples ground with cryogenic grinder SPEX6770. 
Thermogravimetric analyses were performed using a Pyris 1 TGA Perkin Elmer at a heating rate of $10^{\circ} \mathrm{C} / \mathrm{min}$ under nitrogen atmosphere.

Differential Scanning Calorimetry (DSC) analyses were carried out using a NETZSCH DSC200F3 calorimeter. Constant calibration was performed using indium, n-Octadecane and n-Octane standards. Nitrogen was used as the purge gas. 10-15 mg samples were sealed in aluminum pans. The thermal properties were analyzed at 10 ${ }^{\circ} \mathrm{C} /$ min between 20 and $200^{\circ} \mathrm{C}$ to observe the glass transition temperature and the residual curing. All the reported temperatures are inflexion values.

Samples were observed using a FEI Quanta 200 scanning electron microscope and phosphorus content was determined by Energy Dispersive H-Ray spectroscopy (EDX) using Oxford INCA Energy 300 system and a detector of $133 \mathrm{eV}$ (at Mn). Samples were characterized without metallization.

Flammability was assessed using a Pyrolysis-combustion flow calorimeter Fire Testing Technology (FTT) UK. About $3 \mathrm{mg}$ was placed in the pyrolyzer, undergoing an increase of temperature from $20{ }^{\circ} \mathrm{C}$ to $750{ }^{\circ} \mathrm{C}$ at $1{ }^{\circ} \mathrm{C} / \mathrm{s}$ under nitrogen flow. Decomposition gases were sent to a combustor heated at $900{ }^{\circ} \mathrm{C}$ under air flow $\left(\mathrm{N}_{2} / \mathrm{O}_{2}=\right.$ $80 / 20$ ). At this temperature and with $20 \%$ of oxygen, combustion is considered to be complete. Heat release rate was determined by oxygen depletion according to Huggett principle ${ }^{[18]}$ (1 $\mathrm{kg}$ of consumed oxygen corresponds to $13.1 \mathrm{MJ}$ of heat released).

\section{Results and discussion}

\section{1) Synthesis of oligomers MAGLY/MAPC1}

Conventional radical polymerization of methacrylic monomers leads to high molar weight polymers. In an effort to promote compatibility between FR and epoxy resin, the polymerization degree is limited by a chain transfer agent (CTA). Radical chain transfer polymerization (RCTP or telomerization) is chosen for epoxyphosphonate oligomer synthesis. Some types of CTA may be used in RCTP such as thiol or halogenated compounds. With the aim to synthesize non-halogenated FR, halogenated CTA are excluded. Our choice is focused on thiol type CTA, adapted to methacrylic monomers telomerization. In previous studies, the transfer constant of some thiols with methacrylic monomers have been determined ${ }^{[19,20]}$. From these former works, mercaptoethanol was used as CTA, since it shows a transfer constant with methacrylic monomers equal to 0.62 
at $70^{\circ} \mathrm{C}^{[21]}$. In this case, transfer to $\mathrm{CTA}$ is predominant compared to the termination reaction. Theoretical instantaneous polymerization degree $\left(\overline{\mathrm{DP}_{n}}\right)_{i}$ can be determined from equation (1), which is a version of the Mayo equation (2) adapted to radical chain transfer polymerization.

$[\mathrm{XY}]$ represents the CTA concentration and $[\mathrm{M}]$ the monomer concentration.

$$
\begin{array}{ll}
\frac{1}{\left(\overline{\mathrm{DP}_{n}}\right)_{i}}=C_{T} R_{0} & \text { Equation (1) } \\
\frac{1}{\left(\overline{\mathrm{DP}_{n}}\right)_{i}}=\frac{1}{\left(\overline{\mathrm{DP}_{n}}\right)_{0}}+C_{T} \frac{[\mathrm{XY}]}{[\mathrm{M}]} & \text { Equation (2) }
\end{array}
$$

With $\mathrm{R}_{0}=\frac{[\mathrm{XY}]}{[\mathrm{M}]} \quad$ and $\mathrm{C}_{\mathrm{T}}=\frac{\mathrm{K}_{t r}}{k_{p}}$

Thus, the used $\mathrm{R}_{0}$ ratio determines the theoretical DPn of chains formed at low conversion. In our case $\mathrm{R}_{0}$ is set to 0.1 in order to limit DPn around 15 monomer units. Polymerization is carried out in acetonitrile to avoid solvent transfer reaction. Reaction is initiated by $\operatorname{AIBN}\left(0,1 \%_{\text {mol }} /[\right.$ monomers $\left.]\right)$ at $80^{\circ} \mathrm{C}$. MAGLY and MAPC1 are copolymerized with different monomer ratios to assess independently the influence of both FR and phosphorus contents. Experimental conditions are summarized in Scheme 1.

Homopolymers (PolyMAPC1 and PolyMAGLY) are also synthesized in the same conditions.

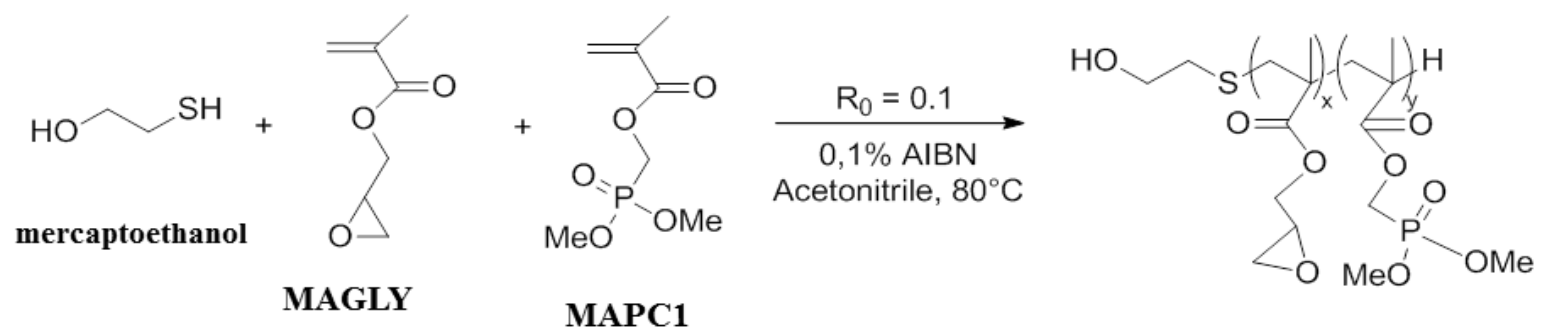

Scheme 1: Radical chain transfer polymerization of Glycidyl methacrylate (MAGLY) with Dimethoxyphosphorylmethylmethacrylate (MAPC1) in presence of mercaptoethanol

\section{$\underline{{ }^{1} \mathrm{H}-\mathrm{NMR} \text { and SEC characterizations }}$}


To identify the signals of epoxy and phosphonate functions ${ }^{1} \mathrm{H}-\mathrm{NMR}$ analyses are carried out. The methoxy protons of phosphonate function are assigned at $3.82 \mathrm{ppm}(\mathbf{d})$ and the proton on the tertiary carbon of epoxy function is assigned at $3.23 \mathrm{ppm}$ (b). Purity can be assessed by quantifying the signals (l) and (k) assigned to monomers. Indeed (l) and (k) signals are characteristic of methacrylic monomers double bond and their quantification shows less than $1 \%_{\text {mol }}$ of monomers.

Experimental MAGLY/MAPC1 ratio is calculated for each cotelomer by comparative integrations of signals (d) (phosphonate) and (b) (epoxy) (Figure S0). The experimental MAGLY/MAPC1 ratios determined are close to the theoretical ones (Table 3). For convenience, oligomers will be named by their respective theoretical MAGLY/MAPC1 ratio. The different phosphorus weight contents are also determined from the experimental MAGLY/MAPC1 ratios. Results are given in table 3.

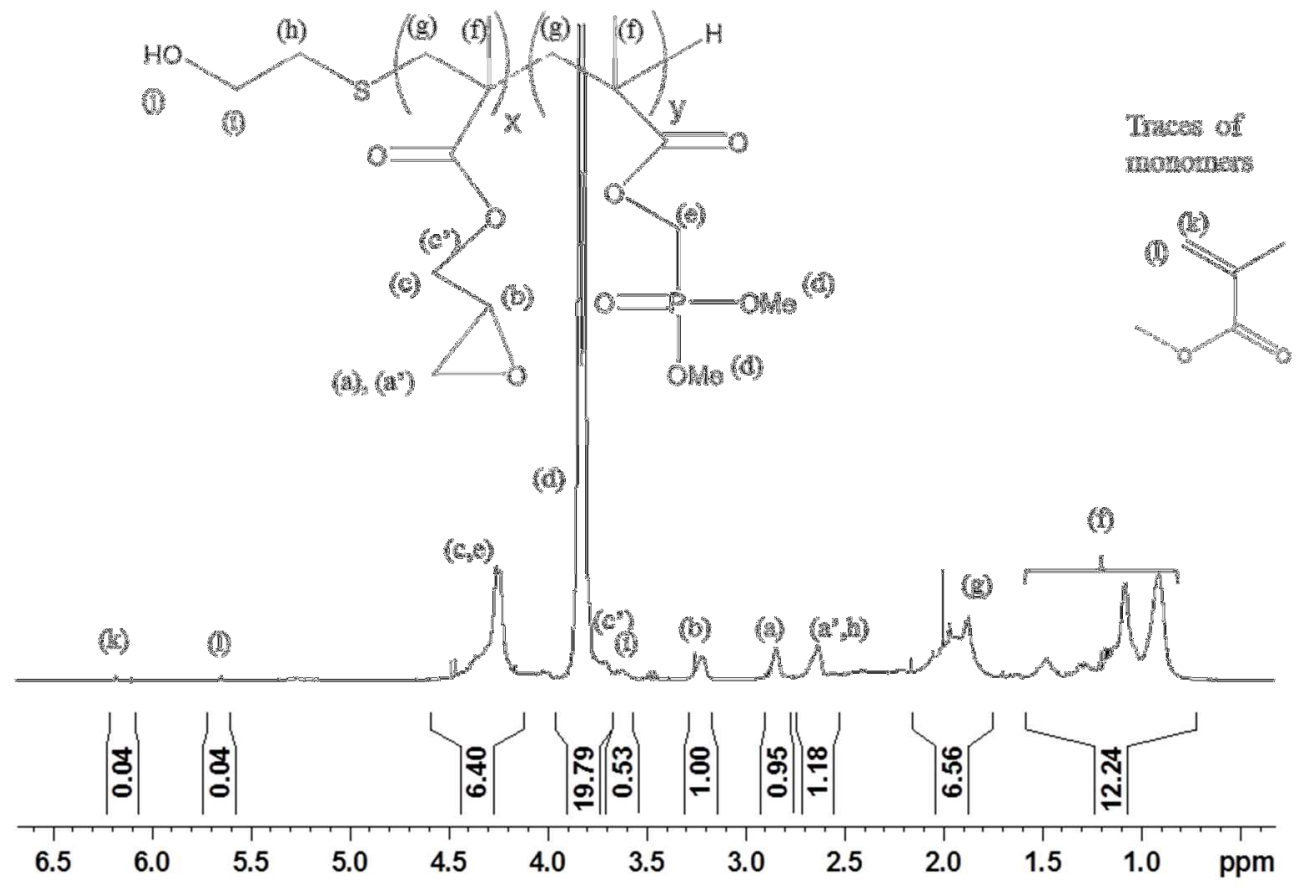

Figure 1: ${ }^{1} \mathrm{H}-\mathrm{NMR}\left(\mathrm{CDCl}_{3}\right)$ of 20EP80P oligomer

Signal (h) is characteristic of protons of one of the secondary carbon of mercaptoethanol. Thus, it is also possible to determine $\mathrm{DP}_{\mathrm{n}}$ by comparative integrations of chain-end-group signals (h) and polymerized unit signals $(\mathbf{b}, \mathbf{d})$. The values of $\mathrm{DP}_{\mathrm{n}}$ determined by ${ }^{1} \mathrm{H}-\mathrm{NMR}$ are given in table 3 . 
Molar mass of oligomers is assessed by steric exclusion chromatography (PMMA standards). These results are given in table 3.

\begin{tabular}{|c|c|c|c|c|c|c|c|c|}
\hline Oligomers & $\begin{array}{c}\text { Theoretical } \\
\text { MAGLY/MAPC1 } \\
\text { ratios }\end{array}$ & $\begin{array}{c}\text { Experimental } \\
\text { MAGLY/MAPC1 } \\
\text { ratios } * *\end{array}$ & $\begin{array}{c}\text { Yield } \\
(\%)\end{array}$ & $\begin{array}{c}\mathrm{Mn}^{*} \\
(\mathrm{~g} / \mathrm{mol})\end{array}$ & $\mathrm{PD}_{\mathrm{i}}^{*}$ & $\mathrm{DP}_{\mathrm{n}}{ }^{*}$ & $\mathrm{DP}_{\mathrm{n}} * *$ & $\begin{array}{c}\text { Experimental } \\
\%_{\mathrm{w}} \mathrm{P}^{* *}\end{array}$ \\
\hline $100 P$ & $0 / 100$ & $0 / 100$ & 67 & 900 & 1.17 & 5 & 7 & 17.5 \\
\hline $20 E P 80 P$ & $20 / 80$ & $24 / 76$ & 59 & 1600 & 1.30 & 9 & 16 & 14.0 \\
\hline $50 E P 50 P$ & $50 / 50$ & $54 / 46$ & 63 & 3100 & 1.74 & 19 & 23 & 9.0 \\
\hline $70 E P 30 P$ & $70 / 30$ & $71 / 29$ & 55 & 2900 & 1.70 & 19 & 22 & 5.9 \\
\hline $100 E P$ & $100 / 0$ & $100 / 0$ & 72 & 3300 & 1.67 & 23 & 20 & 0 \\
& \\
& $*$
\end{tabular}

Table 3: Radical chain transfer copolymerization of MAGLY with MAPC1

A difference between the values of $\mathrm{DP}_{\mathrm{n}}$ determined by ${ }^{1} \mathrm{H}-\mathrm{NMR}$ or SEC is observed. SEC and ${ }^{1} \mathrm{H}-\mathrm{NMR}$ values follow the same trend but the small amount of end chain groups (i) compared to the polymerized monomer units (b,d) makes the ${ }^{1} \mathrm{H}-\mathrm{NMR}$ determination imprecise. $\mathrm{DP}_{\mathrm{n}}$ determined by $\mathrm{SEC}$ are considered more reliable. Furthermore, the higher the amount of the MAGLY fraction, the higher the $\mathrm{DP}_{\mathrm{n}}$. This result shows a better reactivity of MAGLY compared to MAPC1 in radical polymerization but it could also be due to the lower affinity of MAGLY with the CTA.

The polydispersity indexes determined for oligomers 50EP50P, 70EP30P and 100EP, are about 1.70 and are in agreement with those expected for RCTP, typically between 1.5 and $2.0^{[18,19]}$. While those obtained for oligomers 20EP80P and 100P, about 1.17 and 1.30, respectively. It could be due to a solubility of chains in diethyl ether increasing with MAPC1 fraction. This better solubility would lead to solubilization of the smaller chains containing an important fraction of MAPC1. This results in a splitting of the different molar masses during purification and therefore to a reduction of the $\mathrm{PD}_{\mathrm{i}}$ obtained by SEC on purified chains.

\section{2) Determination of oligomers structure: calculation of reactivity ratios}

To ensure the main action of the phosphonate groups in the condensed phase, it seems necessary to reduce their mobility. That is why statistical or alternate distribution of the epoxy functions along the chains is suitable for the FR application. 
To determine the type of macromolecular structure formed during polymerization, reactivity ratios of both monomers are calculated by Jaacks and Macret methods ${ }^{[13]}$. Both methods are based on approximations but allow inferring the synthesized structure. In the Jaacks method, an approximation was made by considering the presence of a single monomer in the calculation. Macret method is based on a first order monomers disappearance kinetics. Jaacks and Macret methods are easily implemented and despite the above-cited approximations, results may allow to assess the structure. Previous works reported in the literature show close reactivity ratios in the case of a copolymerization of MAGLY with MMA $\left(\mathrm{r}_{\mathrm{MAGLY}}=1.05, \mathrm{r}_{\mathrm{MMA}}=0.80{ }^{[15]}\right)$ and MAPC1 with MMA $\left(\mathrm{r}_{\mathrm{MAPCl}}=1.08, \mathrm{r}_{\mathrm{MMA}}=1.00^{[16]}\right)$. In our study, reactivity ratios are expected to be equivalent and close to 1 .

Details concerning the determination of reactivity ratios are given in the supporting information.

Macret method consists in plotting (Figure S1): $\frac{X}{Y}(Y-1)$ vs $\left(\frac{X^{2}}{Y}\right)$, with $X=\frac{\left[M_{1}\right]}{\left[M_{2}\right]}$ and $Y=\frac{d\left[M_{1}\right]}{d\left[M_{2}\right]}$

Thus, a straight line is obtained and reactivity ratios, determined from the slope and the intercept, are $\mathrm{r}_{\mathrm{MAPCl}}=$ 0.78 and $\mathrm{r}_{\mathrm{MAGLY}}=1.28$. The product $r_{M A G L Y} \times r_{M A P C 1}$ lower than 1 allows deducing a statistical structure for the synthesized oligomers.

According to Jaacks method (Figure S2), $\mathrm{r}_{\mathrm{MAPC} 1}=0.84$, which is in good agreement with the value obtained by Macret method. The reactivity ratio values obtained are consistent with those found in the literature ${ }^{[22]}$. MAGLY is slightly more reactive than MAPC1 in radical copolymerization with MMA ${ }^{[13-16]}$. Steric hindrance caused by phosphonate group may be responsible for the lower reactivity of MAPC1.

However, reactivity ratios are determined for the first stages of polymerization. Conversion of both monomers was followed by means of ${ }^{1} \mathrm{H}-\mathrm{NMR}$ during the entire polymerization reaction (Figure S3) for the 70EP30P oligomer. The $\mathrm{R}$ ratio, representing the MAGLY/MAPC1 ratio in the monomer mixture; is calculated by integrating the signals (b) and (a), i.e. $\mathrm{R}=(\mathrm{b}) /(\mathrm{a})$. At $\mathrm{t}_{0,} \mathrm{t}_{4 \mathrm{~h}}, \mathrm{t}_{8 \mathrm{~h}}$ and $\mathrm{t}_{24 \mathrm{~h}}, \mathrm{R}$ values are respectively 72/28, 74/26, $73 / 27$ and 76/24 and are considered to be equivalent. R is constant until the end of RCTP; it shows similar consumption rates and thus similar reactivity for both methacrylates. Despite different reactivity ratios calculated using Macret and Jaacks methods, ${ }^{1} \mathrm{H}-\mathrm{NMR}$ analyses performed at high conversion rate do not show faster consumption of MAGLY compared to MAPC1 (Figure S3). 
Radical chain transfer polymerization of MAGLY with MAPC1 in presence of thiol-based CTA has been used for 5 oligomers synthesis. It leads to low molecular weight epoxy/phosphonate cotelomers. A statistical chain structure was assumed from the calculation of reactivity ratios and from the consumption rate of monomers. Oligomers exhibit an experimental MAGLY/MAPC1 ratio close to the theoretical ones. Phosphorus content has been determined and ranges from 5.9 to $14.0 \%_{\mathrm{w}}$ for cotelomers and from 0 to $17.5 \%_{\mathrm{w}}$ for homotelomers. These results have been used to prepare materials with defined phosphorus contents.

\section{3) Introduction of oligomers FR in epoxy resin, characterization of thermal and flame retardant properties of materials}

\section{Thermal stability of oligomers FR}

Figure 2 represents TGA thermograms performed for all oligomers. Concerning the thermal stability, it shows that the thermal degradation starts beyond $160^{\circ} \mathrm{C}$ for all FR. It also shows that phosphorus oligomers exhibit around $30 \%_{\mathrm{w}}$ of char at $700^{\circ} \mathrm{C}$, while non phosphorus oligomer, i.e. $100 \mathrm{EP}$, only exhibits a $1.8 \%_{\mathrm{w}}$ char residue. These results evidence the action of phosphorus in the condensed phase. However, FR $100 P$ with $17.5 \%_{\mathrm{w}} \mathrm{P}$ generates a lower char amount than others oligomers with less phosphorus content. According to this result, we assume that there is an interaction between epoxy and phosphonate functions, which contributes to higher charring and implies existence of an optimal phosphorus content beyond which char amount remains constant or decreases. Vahabi et al. ${ }^{[23]}$ showed similar results on MMA-MAPC1 copolymers.

Thermal stability of oligomers will be taken into account during the curing of the epoxy material. 


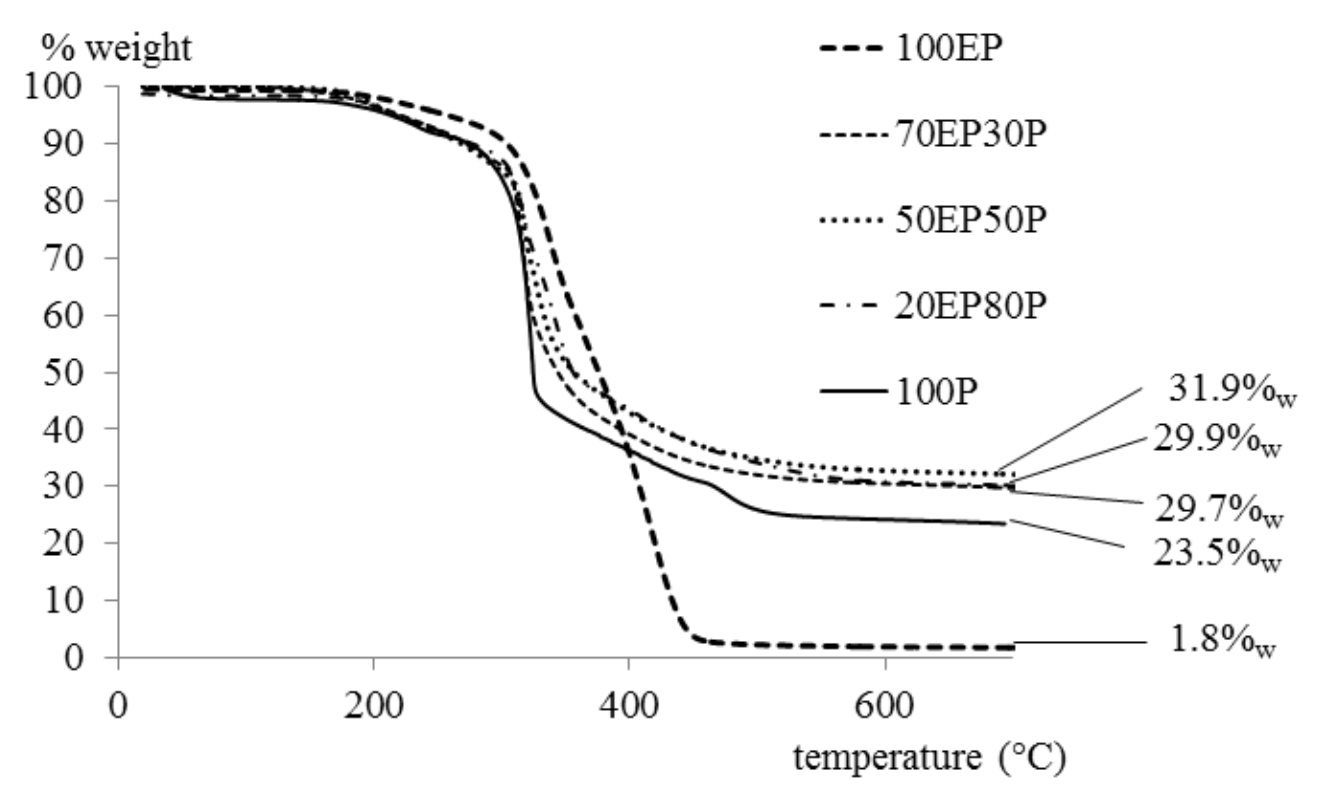

Figure 2: TGA thermograms of oligomers 100EP, 70EP30P, 50EP50P, 20EP80P, 100P under nitrogen atmosphere at $10^{\circ} \mathrm{C} / \mathrm{min}$

In order to evaluate the fire behavior of the prepared reactive phosphorus FR, they have been introduced in a conventional epoxy matrix, i.e. a resin Diglycidylether of Bisphenol A (DGEBA, Figure 3(a)) cured by Isophorone diamine (IPDA, Figure 3(b)). The matrix is chosen according to FR degradation temperature; which has to be higher than curing temperature to avoid FR degradation during material cross-linking. Epoxy/amine ratio is fixed to $2 / 1$ because the reaction between an epoxy function and a primary amine forms a secondary amine which is then able to react once again with another epoxy function ${ }^{[24]}$. Materials are then formulated maintaining epoxy/amine ratio (2/1) in order to avoid impacting cross-linking. Indeed, material thermal stability is directly dependent on the cross-linking density.

\section{Incorporation in epoxy matrix and assessment of the compatibility between FR and matrix}

DGEBA has an aromatic structure which leads to rigid networks with excellent mechanical properties and good chemical inertness. That is why DGEBA is widely used, especially in the production of coating or high performance composite ${ }^{[25,26]}$. Nevertheless, flammability of these materials requires introduction of FR in their formulations. Isophorone diamine is a cycloaliphatic hardener, more reactive than an aromatic one. 
a)

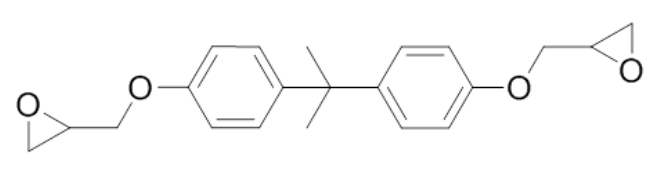

b)

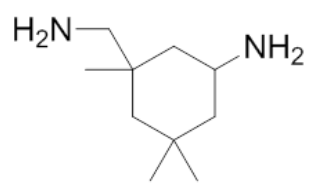

Figure 3: a) Diglycidylether Bisphenol A (DGEBA), b) Isophorone diamine (IPDA)

Before the curing of epoxy materials, DSC analysis of DGEBA/IPDA (2/1) system was used to highlight its reactivity. DSC curve (Figure 8, dotted line) shows an exothermal peak at $115^{\circ} \mathrm{C}$, which corresponds to the condensation of a primary amine with an epoxy function. Another peak at $147^{\circ} \mathrm{C}$ corresponds to a second condensation of the resulting secondary amine with a second epoxy function. These results show that curing occurs below $160^{\circ} \mathrm{C}$, which will prevent FR degradation.

The reactivity of $100 E P$ epoxy functions with secondary amines has already been demonstrated by Iwakura et al. ${ }^{[10]}$. To evaluate the reactivity of FR epoxy functions with IPDA amines, the system 100EP/IPDA was analyzed in DSC. Full-line curve (Figure 4) shows an unique exothermal peak at $108^{\circ} \mathrm{C}$. For this system, the reaction with primary or secondary amines cannot be dissociated. The two systems DGEBA/IPDA and 100EP/IPDA react in the same temperature range, which allows FR to be efficiently incorporated into the network during cross-linking. In order to avoid freezing of the system during curing and to ensure optimal crosslinking, it is necessary to slow down crosslinking reaction. Thus, materials were first cured at $\mathrm{T}<\mathrm{T}$ DSC crosslinking peak then at $\mathrm{T}>\mathrm{T}$ DSC crosslinking peak ; therefore curing was carried out using the following temperature program: $4 \mathrm{~h}$ at $80^{\circ} \mathrm{C}$ followed by $10 \mathrm{~h}$ at $150^{\circ} \mathrm{C}$. Different materials were prepared with various $\mathrm{FR}$ and phosphorus rates. Material are named according to their phosphorus content followed by the used oligomer: "x\% P(used oligomer)". 


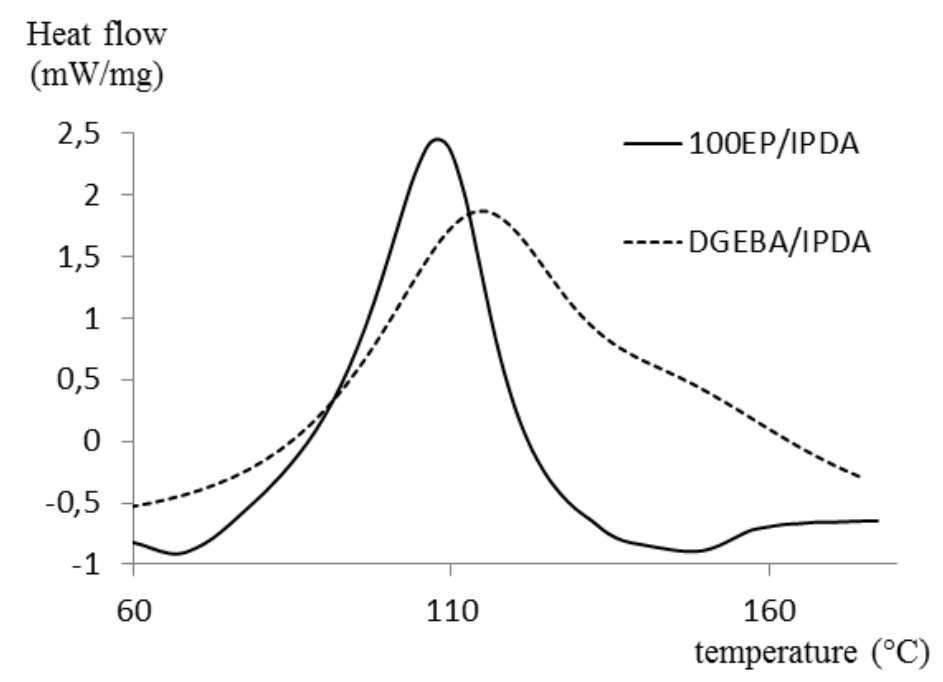

Figure 4: DSC analyses of 100EP/IPDA and DGEBA/IPDA systems operated at $10^{\circ} \mathrm{C} / \mathrm{min}$

A possible incompatibility between the matrix and the FR could lead to phase segregation. During early stages of curing, fluidity of the system increases and may allow sedimentation or creaming of segregated phases. The homogeneity of the cured materials was studied by scanning electron microscopy with EDX technology (Energy Dispersive X-ray). Phosphorus content was determined in different areas of a material cross-section. Figure 5(a) represents a SEM picture of the material 2.1\%P(20EP8OP) and shows the different areas where phosphorus content was quantified. Area 1 corresponds to the top and area 3 to the bottom of the material. Phosphorus contents determined are equivalent $\left(1.59 \%_{\mathrm{w}} \mathrm{P} ; 1.72 \%_{\mathrm{w}} \mathrm{P}\right.$ and $\left.1.64 \%_{\mathrm{w}} \mathrm{P}\right)$ in the whole surface. This result shows the absence of segregated phases and confirms the compatibility between FR and matrix. All materials containing FR were analyzed by this method, and results are similar except for the material $3 \% P(100 P)$, for which different phosphorus contents are determined in different areas of the cross-section. Phosphorus content is higher at the bottom area than at the top one of the sample (Figure 5(b)). These results show the necessity of having a reactive FR system to obtain a homogeneous material. Reactive oligomers are immobilized from the start of crosslinking whereas non-reactive oligomers keep their mobility for a longer period allowing their migration. 

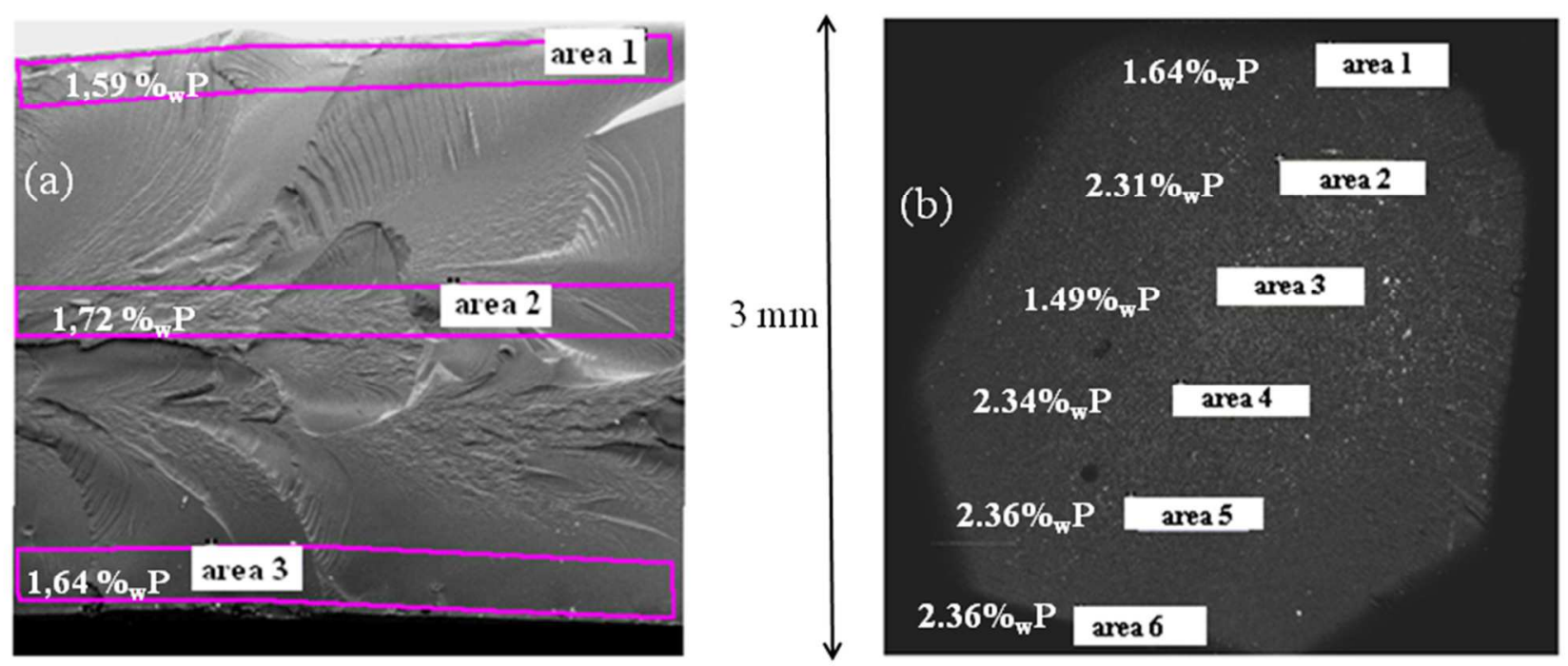

Figure 5: (a) Cross-section of the material 2.1\%P (20EP80P), (b) Cross-section of the material 3\%P (100P)

DSC analyses were performed on cured materials (Figure 10). Tg values of the material $0.8 \% P(70 E P 30 P$ ) is about $5^{\circ} \mathrm{C}$ lower than that of the reference material while materials $0.9 \% P(50 E P 50 P)$ and $1 \% P(20 E P 80 P)$, i.e. containing similar phosphorus content, exhibit a Tg comparable to that of the reference $\left(144.4^{\circ} \mathrm{C}\right)$. The use of an oligomer rich in epoxy functions slightly decreases the $\mathrm{Tg}$ of the material, which is not suitable for the crosslinking density and for the FR application since it could impact the thermal stability.

Beyond their Tg, all materials present residual crosslinking. The total crosslinking energy of material reference and $0.9 \% P(50 E P 50 P)$ are respectively $\Delta \mathrm{H}=395 \mathrm{~J} / \mathrm{g}$ and $\Delta \mathrm{H}=406 \mathrm{~J} / \mathrm{g}$. These values are considered as equivalent. Energy associated to this residual crosslinking $(\Delta \mathrm{H})$ is measured between $\mathrm{Tg}$ and $200^{\circ} \mathrm{C}$ as shown in the figure 6 , for the materials containing around $1 \%{ }_{\mathrm{w}} \mathrm{P}$. The material $0.8 \% P(70 E P 3 O P)$ presents a $\Delta \mathrm{H}(=18.3$ $\mathrm{J} / \mathrm{g})$, higher than the reference material $(\Delta \mathrm{H}=9.6 \mathrm{~J} / \mathrm{g})$. This loss of crosslinking observed on this material may be attributed to the dimension $\left(\mathrm{DP}_{\mathrm{n}}\right)$ of the FR. Indeed the higher loss of crosslinking is observed with the material containing the longer chain $\left(70 \mathrm{EP} 30 \mathrm{P}, \mathrm{DP}_{\mathrm{n}}=19\right)$. This dimension reduces the mobility of the FR chains during crosslinking and does not allow the totality of the epoxy functions to react before the increase of material viscosity during the curing. The residual crosslinking measured less than $5 \%$ of the total crosslinking energy of the reference material, thus it will only slightly affect the thermal behavior of the materials.

The low mobility of prepared oligomers can be useful to immobilize FR in the bulk and to avoid migration during the lifetime of the materials. However it also reduces the crosslinking of the material. It seems better to 
use a reactive oligomer bearing only few epoxy functions as to avoid impacting negatively the material crosslinking and the properties which depend up on.

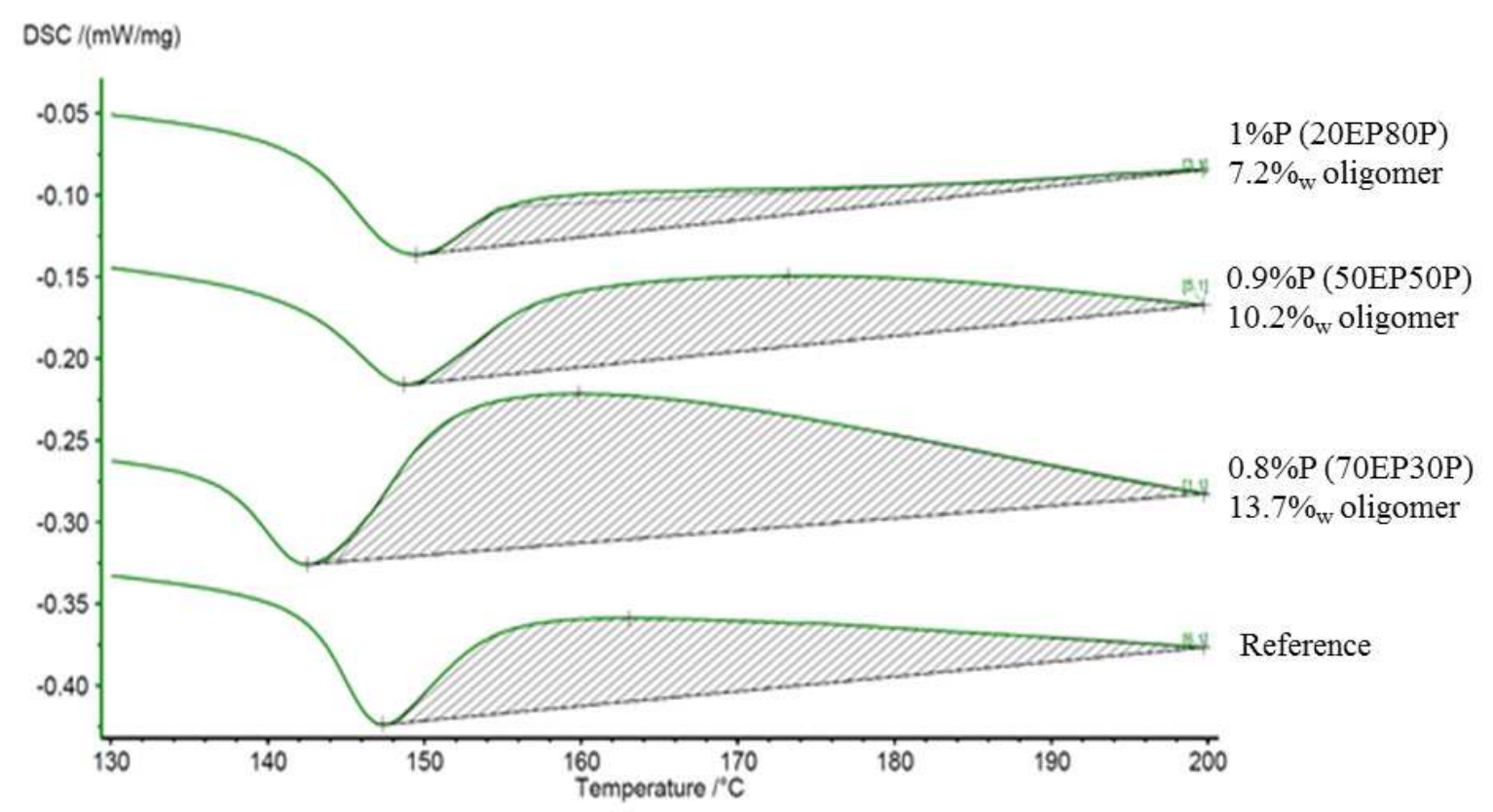

Figure 6: DSC analyses $\left(10^{\circ} \mathrm{C} / \mathrm{min}\right)$ of the materials

$$
\begin{gathered}
\text { reference, } \mathrm{Tg}=144.4^{\circ} \mathrm{C}, \underline{\Delta \mathrm{H}=9.6 \mathrm{~J} / \mathrm{g}}-0,8 \% \mathrm{P}(70 \mathrm{EP30P}), \mathrm{Tg}=140.0^{\circ} \mathrm{C}, \underline{\Delta \mathrm{H}=18.3 \mathrm{~J} / \mathrm{g}} \\
0,9 \% P(50 \mathrm{P} 50 \mathrm{P}), \mathrm{Tg}=145.8^{\circ} \mathrm{C}, \underline{\mathrm{H}=9.2 \mathrm{~J} / \mathrm{g}}-1 \% \mathrm{P}(20 E P 80 \mathrm{P}), \mathrm{Tg}=145.3^{\circ} \mathrm{C} \Delta \mathrm{H}=3.9 \mathrm{~J} / \mathrm{g}
\end{gathered}
$$

\section{4) Thermal properties and flammability of prepared materials}

Phosphorus FR are known for their different flame-retardancy mechanisms. They can act in gas and/or in condensed phases ${ }^{[27]}$. In the gas phase, they act like the halogenated FR. Thermal decomposition of phosphorus group can generate radical species $\mathrm{PO}_{2}^{\circ}, \mathrm{PO}^{\circ}$ and $\mathrm{HPO}^{*}$, which scavenge the $\mathrm{H}^{\circ}$ and $\mathrm{OH}^{\circ}$ radicals, slowing and even reducing the combustion efficiency. In the condensed phase, chains dehydroxylation due to the action of phosphoric acid on the hydroxyl groups, leads to conjugated structures, and then to polyaromatic structures by Diels-Alder cyclization. The char formed acts as a barrier against heat and gas $\left(\mathrm{O}_{2}\right.$ and pyrolysis gases).

The flammability of the different materials is assessed according to different parameters such as high temperature char amount, heat release rate or total heat released during decomposition. Materials are characterized by thermogravimetric and PCFC analyses to highlight the effects of FR on thermal properties and flammability. 


\section{Thermogravimetric analyses (TGA)}

TGA analyses are performed under nitrogen flow to assess the influence of FR on thermal stability and charring. The selected heating rate is $10^{\circ} \mathrm{C} / \mathrm{min}$ up to $700^{\circ} \mathrm{C}$. TG and DTG curves of reference, $0 \% P(100 E P)$, $2.1 \% P(70 E P 30 P), 3 \% P(20 E P 80 P), 3 \% P(100 P)$ are presented in Figures 7 and 8 . It can be observed that reference and $0 \% P(100 E P)$ exhibit very similar curves and their onset of degradation $\mathrm{T}_{10}\left(\mathrm{~T}_{10}\right.$ represents temperature at which the material loses $10 \%$ of its initial mass) is almost the same $\left(368^{\circ} \mathrm{C}\right.$ against $\left.364^{\circ} \mathrm{C}\right)$. Thus the introduction of a non-phosphorus reactive oligomer (100P) in the material does not affect its thermal stability. The thermograms point out also that the decomposition pathway of the materials changes from a single step mechanism to a two-step mechanism when incorporating the phosphorous oligomer in the matrix. Moreover the thermal stability of the epoxy matrix is affected by the presence of phosphorus. Figure 9(a) shows the evolution of $\mathrm{T}_{10}$ with their initial phosphorus content. Compared to the reference, the thermal stability is reduced by about $50^{\circ} \mathrm{C}$ for the materials which contain $3 \%_{\mathrm{w}} \mathrm{P}$.

The lower degradation temperatures could be assigned to the early decomposition of phosphorus-containing groups. Literature describes the phosphonic-ester decomposition between 300 and $340^{\circ} \mathrm{C}$ by alkyl chain loss ${ }^{[28]}$. It may be assumed that phosphonic-ester decomposition generates radical species which initiate the matrix decomposition. The presence of phosphorous acids provokes dehydration and favors charring of the epoxy matrix by different mechanisms including the formation of P-O-P bonds by intramolecular condensation ${ }^{[29]}$. It is to note that the thermal stability $\mathrm{T}_{10}$ is strongly dependent of the phosphorus content but almost insensitive to the polymer structure since $3 \% P(20 E P 80 P)$ and $3 \% P(100 P)$ exhibit very similar thermograms. It should be added that the presence of phosphorus tends to reduce the degradation rate as proved by the DTG curves.

Figure 9(b) shows the evolution of the char yield at $700^{\circ} \mathrm{C}$ as the function of the initial phosphorus content of the materials. Once again, it can be underlined that reference and $0 \% P(100 E P)$ exhibit similar behavior with respective char contents of $8.6 \% \mathrm{w}_{\mathrm{w}}$ and $8.1 \%_{\mathrm{w}}$. It can be observed that the char yield increases proportionally to phosphorus ratio. The $3 \% P(20 E P 80 P)$ sample gives $15.9 \%_{\mathrm{w}}$ of residue, twice the char content obtained with

the reference $(8.1 \% \mathrm{w})$. These results can be correlated with those found in the literature. Perez et al. ${ }^{[30]}$ showed a similar result in a DGEBA/DDS matrix. Char content is two times higher with $3 \%_{\mathrm{w}} \mathrm{P}\left(27 \%_{\mathrm{w}}\right.$ versus 
$14 \%_{\mathrm{w}}$ for the phosphorus-free material). The higher char contents of this study are due to the use of an aromatic hardener. Indeed, aromatic structures are known to promote the charring effect.

SEM/EDX showed the heterogeneity of the $3 \% P(100 P)$ sample, thus it is totally ground and homogenized to be characterized in its entirety. $3 \% P(100 P)$ gives $17.5 \%$ w of char. This content is slightly higher than the content obtained with the $3 \% P(20 E P 8 O P)$ sample which gives $15.9 \%{ }_{\mathrm{w}}$ of residue. This slight difference does not prove a better FR activity of non-reactive oligomers in the condensed phase. Indeed it must be reminded that the experimental phosphorus content of $100 P$ oligomer is higher than that of $20 E P 80 P$ (see Table 3 ). Thus, the difference could be mainly assigned to deviation of the formulation. Nevertheless, this result shows that even non-reactive FR oligomers acts also in the condensed phase. $\mathrm{DP}_{\mathrm{n}}$ around 20 seems to be a sufficient condition to ensure a good action of FR chains in the condensed phase.

From thermal analysis results, it can be concluded that the phosphorus oligomers used in epoxy resin act mainly in the condensed phase by promoting char formation during thermal decomposition. The phosphorus content seems to be the key parameter influencing the thermal behavior of the materials and not the oligomer amount. It was also highlighted that the grafting degree of FR to matrix has no significant influence on the thermal behavior of the materials.

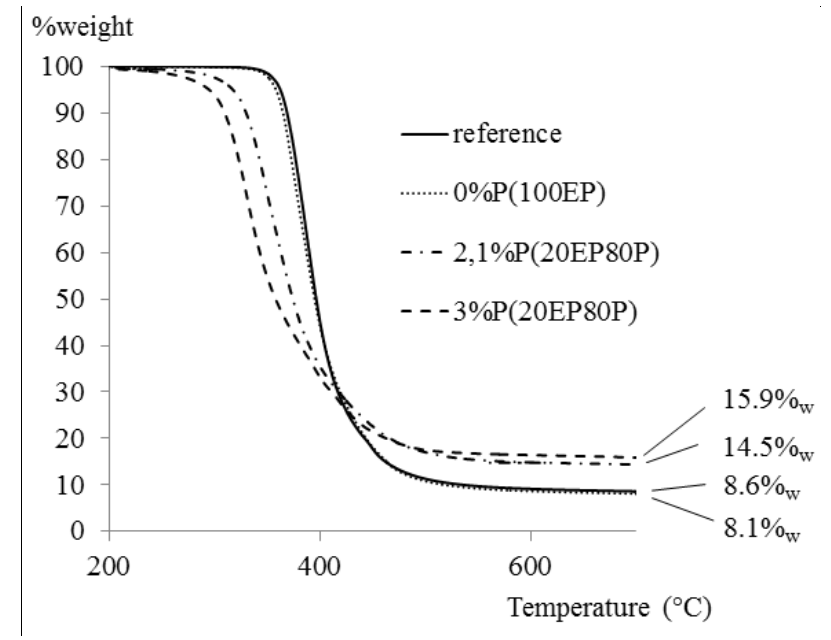

Figure 7: TGA curves of reference, $0 \% \mathrm{P}(100 \mathrm{EP})$, $2.1 \%$ P (70EP30P), 3\%P(20EP80P)materials under nitrogen atmosphere at $10^{\circ} \mathrm{C} / \mathrm{min}$

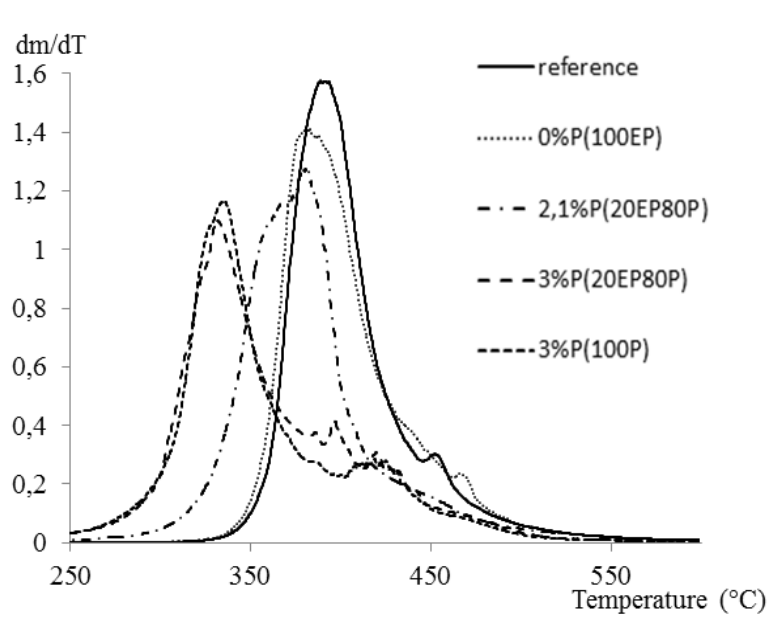

Figure 8: DTG curves of reference, $0 \% P(100 E P)$, $1 \% P(70 E P 30 P), 3 \% P(20 E P 80 P)$ materials under nitrogen atmosphere at $10^{\circ} \mathrm{C} / \mathrm{min}$ 

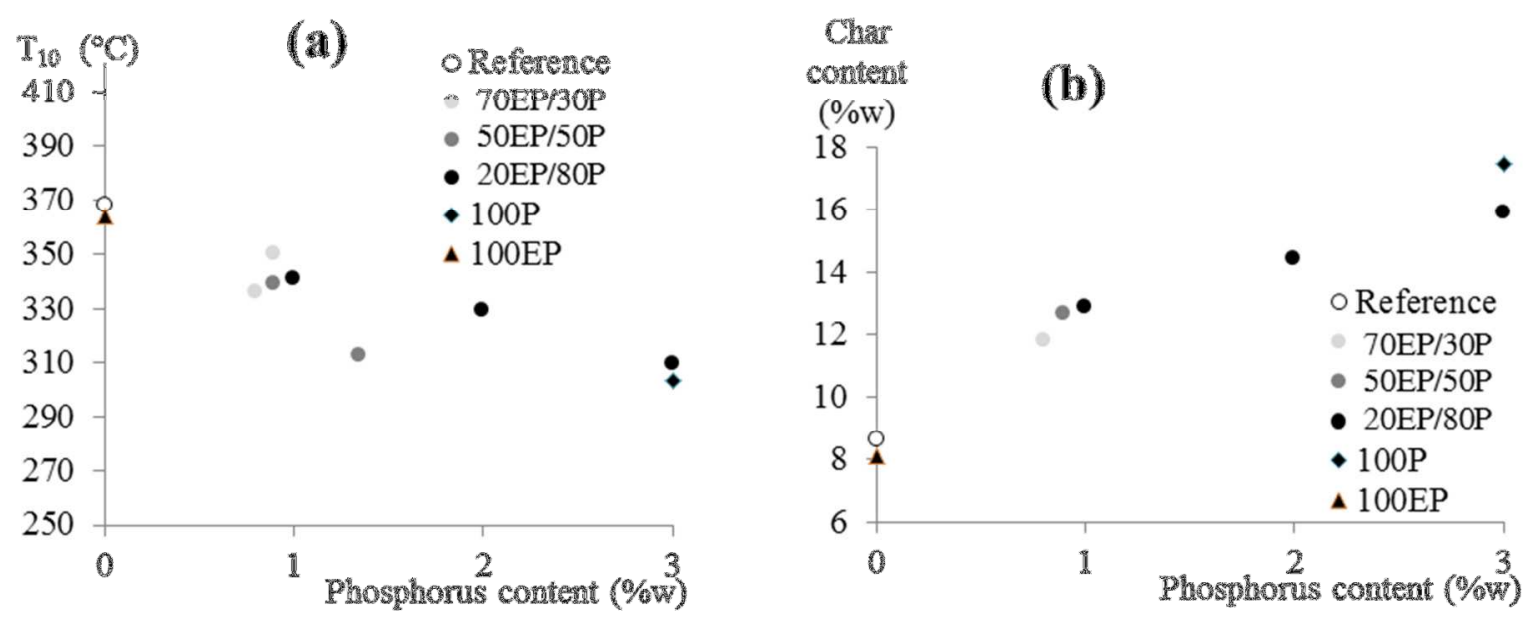

Figure 9: Evolution of $\mathrm{T}_{10}$ (a) and char content (b) versus initial phosphorus content of all materials

\section{Microcalorimetry characterization (PCFC)}

In order to assess the flame retardant properties of synthesized oligomers, materials are characterized by pyrolysis/combustion flow calorimetry. PCFC analyses reproduce combustion processes by material pyrolysis under inert atmosphere followed by the high temperature oxidation of decomposition products ${ }^{[31]}$. The most representative parameters flammability, i.e. $\mathrm{T}_{10}, \mathrm{~T} \alpha$, THR, pHRR are summarized in Table $4 . \mathrm{T}_{10}$ is given by TGA analyses and T $\alpha$ represents the maximal heat flow temperature. The total heat released (THR) is obtained by integration of PCFC curves. SumHRC is the sum of peaks from deconvolution of HRR peaks divided by heating rate. The effective heat of combustion (EHC) represents the released heat by lost mass; it is obtained by dividing THR by mass loss and char rate (obtained from TGA analyses).

The reference values for pHRR and THR are respectively $634 \mathrm{~W} / \mathrm{g}$ and $27.5 \mathrm{~kJ} / \mathrm{g}$. Non-phosphorus material $(0 \% P(100 E P))$ presents a fire behavior close to reference. If we compared the nature of oligomer used as FR in epoxy material, the HRR curves (Figure 10) of the 0.8\%P(70EP30P), 0.9\%P(50EP50P), $1 \% P(20 E P 80 P)$ materials show equivalent profiles. Their pHRR values (table 4) are around 450W/g, THR values around 24.5 $\mathrm{kJ} / \mathrm{g}$ and they present lower $\mathrm{T} \alpha$ than the reference and $0 \% P(100 E P)$ materials. This decrease of thermal stability, already observed with TGA analyses is due to the decomposition of phosphorous groups. Thus, the reduction of characteristic parameters and the decrease of thermal stability observed with the three materials $0.8 \% P(70 E P 30 P), 0.9 \% P(50 E P 50 P), 1 \% P(20 E P 80 P)$ can be attributed to the phosphorus content onto the FR. It also can be concluded that the oligomer amount does not influence flammability of materials. 
Then, the influence of the phosphorus content is presented on Figure 11 with PCFC curves of materials reference, $0 \% P(100 E P), 0.9 \% P(70 E P 30 P), 1.35 \% P(50 E P 50 P), 2.1 \% P(20 E P 80 P)$ and $3.0 \% P(20 E P 80 P)$. It can be observed that the thermal stability decreases with increasing phosphorus content. Decomposition starts at about $275^{\circ} \mathrm{C}$ for the $3 \% P(20 E P 80 P)$ material. Flammability parameters are also influenced by phosphorus content. With $3 \%{ }_{\mathrm{w}} \mathrm{P}$, THR is reduced by $25 \%$ and pHRR by $60 \%$ compared to reference. Phosphorus materials decompose earlier and slower, which allow char formation which slows and reduces the heat release.

Lastly, the PCFC curves of the two $3 \% P$ materials are compared to the reference on Figure 12. The two materials $3 \% P(20 E P 80 P)$ and $3 \% P(100 P)$ have close flammability, their respective pHRR values are 255 and $258 \mathrm{~W} / \mathrm{g}$. Thus, covalent FR grafting to matrix does not influence significantly the pHRR, however THR and EHC values of material $3 \% P(100 P)$ are comparable to the values obtained on materials containing about $1 \%{ }_{\mathrm{w}} \mathrm{P}$ brought by reactive FR. The slight THR decrease compared to the material reference is probably due to charring promotion. The difference between EHC values of material $3 \% P(100 P)$ and $3 \% P(20 E P 80 P)$ could be due to a lower action in gas phase for non-reactive oligomer than for reactive one. Figure 13 represents the variation of THR (a), EHC (b) and pHRR (c) versus the phosphorus content for the different systems used.

In summary, the above results illustrate that the oligomers introduced with more than $1.5 \%{ }_{\mathrm{w}} \mathrm{P}$ can effectively improve the flame retardancy of the epoxy resins.

\begin{tabular}{|c|c|c|c|c|c|c|}
\hline Materials & $\left.\mathbf{T}_{\mathbf{1 0}}{ }^{\circ} \mathbf{C}\right)$ & $\mathbf{T}_{\mathbf{\alpha}}\left({ }^{\circ} \mathbf{C}\right)$ & $\begin{array}{c}\text { pHRR } \\
(\mathbf{W} / \mathbf{g})\end{array}$ & $\begin{array}{c}\text { Sum } \\
\text { HRC } \\
(\mathbf{J} / \mathbf{g} \cdot \mathbf{K})\end{array}$ & $\begin{array}{c}\text { THR } \\
(\mathbf{k J} / \mathbf{g})\end{array}$ & $\begin{array}{c}\text { EHC } \\
(\mathbf{k J} / \mathbf{g})\end{array}$ \\
\hline reference & 368 & 382 & 634 & 625 & 27.5 & 30.1 \\
\hline $\mathbf{0 \% P ( 1 0 0 E P )}$ & 364 & 374 & 578 & 640 & 25.5 & 27.7 \\
\hline $\mathbf{0 . 8 \% P ( 7 0 E P 3 0 P )}$ & 336 & 362 & 459 & 490 & 24.2 & 27.1 \\
\hline $\mathbf{0 . 9 \%} \mathbf{P ( 5 0 E P 5 0 P )}$ & 339 & 360 & 443 & 461 & 24.6 & 27.9 \\
\hline $\mathbf{1 \% P ( 2 0 E P 8 0 P )}$ & 341 & 368 & 466 & 505 & 24.7 & 28.3 \\
\hline $\mathbf{0 . 9 \%} \mathbf{P ( 7 0 E P 3 0 P )}$ & 350 & 361 & 447 & 490 & 24.9 & 28.5 \\
\hline $\mathbf{1 . 3 5 \% P ( 5 0 E P 5 0 P )}$ & 312 & 365 & 448 & 471 & 24.4 & 28.5 \\
\hline $\mathbf{2 \% P ( 2 0 E P 8 0 P )}$ & 329 & 347 & 327 & 368 & 22.2 & 25.9 \\
\hline $\mathbf{3 \% P ( 2 0 E P 8 0 P )}$ & 309 & 342 & 255 & 332 & 20.5 & 24.4 \\
\hline $\mathbf{3 \% P \% ( 1 0 0 P )}$ & 303 & 336 & 284 & $\mathrm{X}$ & 24.4 & 29.6 \\
\hline
\end{tabular}




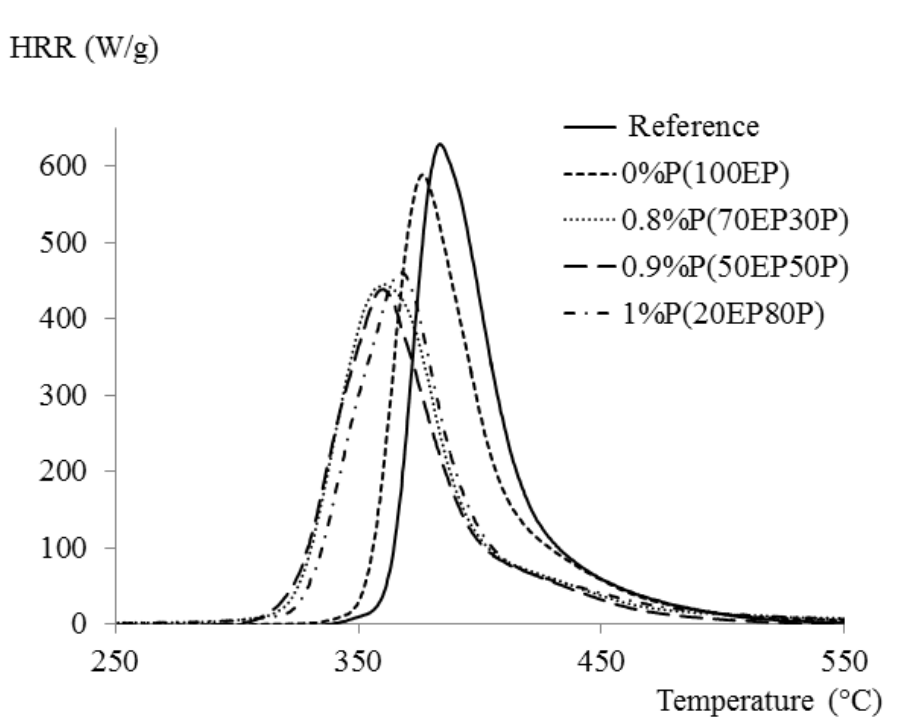

Figure 10: PCFC curves of the reference, 0\%P(100EP), 0.8\% P(70EP30P $)$, $0.9 \% P(50 E P 50 P), 1 \% P(20 E P 80 P)$ materials

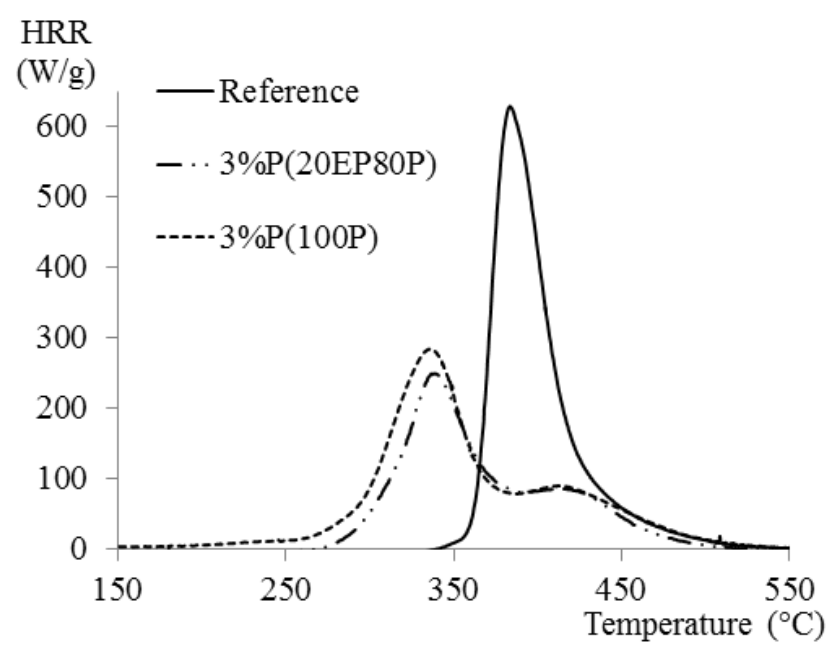

Figure 12: PCFC curves of the reference, $3 \% P(20 E P 80 P)$ et $3 \% P(100 P)$ materials

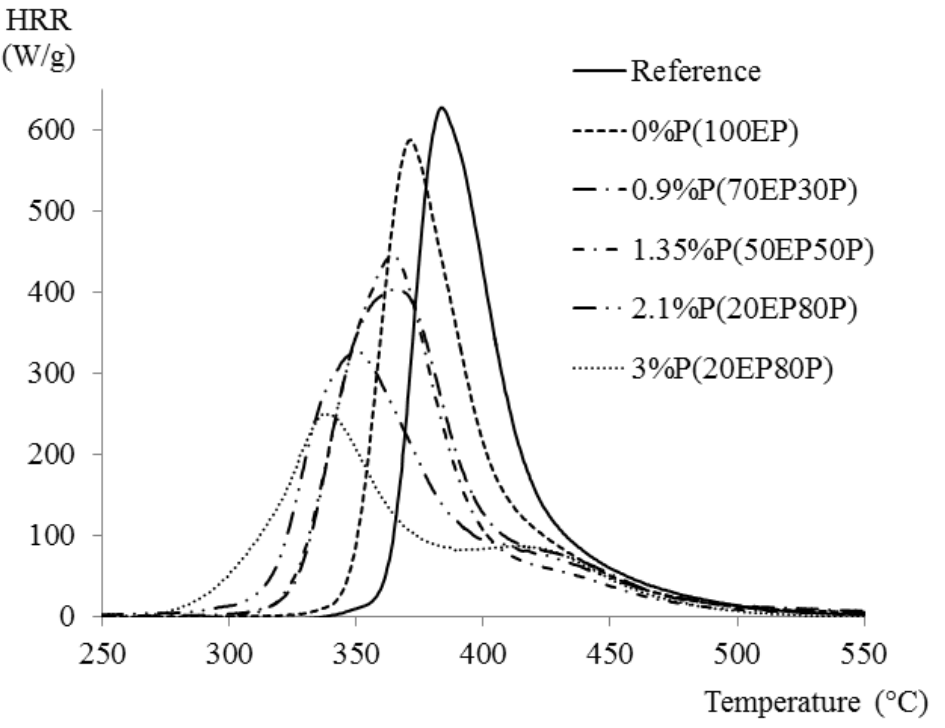

Figure 11: PCFC curves of the reference, 0\%P(100EP), 0.9\%P(70EP30P), 1.35\%P(50EP50P), $2.1 \% P(20 E P 80 P), 3.0 \% P(20 E P 80 P)$ materials 


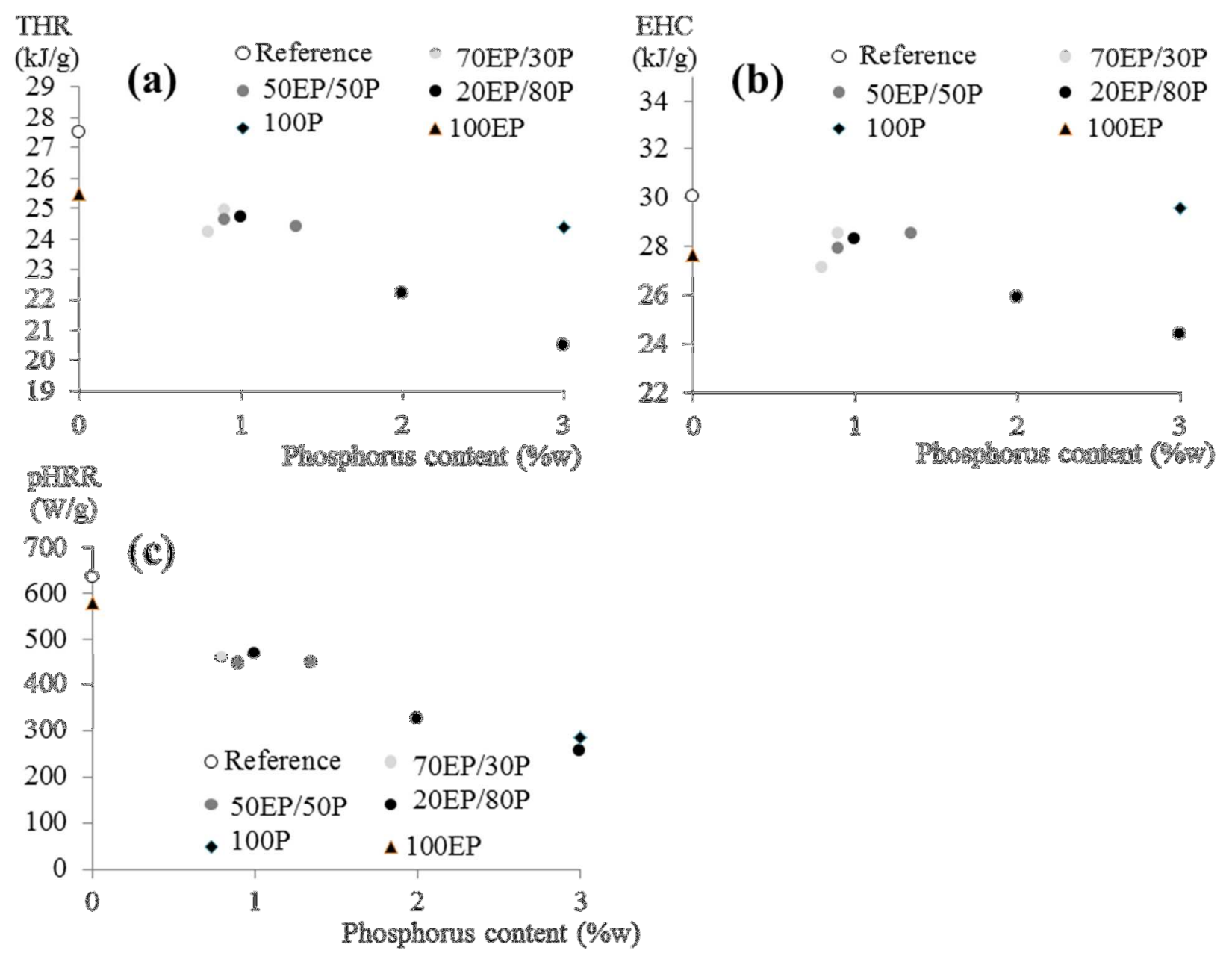

Figure 13: Evolution of THR (a), EHC (b) and pHRR (c) versus initial phosphorus content of all materials

\section{Conclusion}

For the first time, original (co)oligomers of MAGLY with MAPC1 in various ratios were synthesized. Radical chain transfer polymerization in the presence of thiol type CTA has effectively been used to synthesize these low molecular weight phosphorus reactive FR. A kinetic study shows equivalent reactivity for the two monomers and thus a statistical structure of oligomeric chains was evidenced. Flame retardant properties of these oligomers have been evaluated in an epoxy matrix. Incomplete crosslinking of these reactive FR is observed by DSC analyses; it can be attributed to the low mobility which does not allow complete reaction of epoxy functions. To preserve physical properties of material, it is preferable to use an oligomer mainly composed of MAPC1, which allows a crosslinking level comparable to the reference. However, material 
prepared with non-reactive phosphorus FR present phases segregations; it shows that oligomer reactivity is necessary to ensure material viability.

TGA and PCFC analyses show that the oligomer FR content cannot influence material flammability, which depends only on the phosphorus content. A decrease in the thermal stability is observed on phosphorus materials, and is attributed to the earlier decomposition of phosphorus groups. Nevertheless this decrease in thermal stability is accompanied by a significant increase in char yield and reduction of flammability, indeed with $3 \%_{\mathrm{w}} \mathrm{P}$, THR is reduced by $25 \%$ and pHRR by $60 \%$ compared to the reference. Comparison of materials with $3 \%_{\mathrm{w}} \mathrm{P}$ brought by reactive or non-reactive oligomer allows to determine that oligomer reactivity is necessary to ensure homogeneity of material and to reduce heat release. Oligomeric nature of non-reactive FR is a sufficient condition to obtain a main FR-mode-of-action in the condensed phase slowdown of the heat

release. Real fire conditions tests on larger specimens could highlight the impact of the heterogeneity on flammability. Mechanical characterization could also be used to assess the influence of materials heterogeneity on mechanical properties.

\section{Acknowledgements}

The authors thank Jean-Marie Taulemesse for the MEB/EDX observations and Chad Friesen for his precious help. 


\section{References}

[1] REACH, Commission of regulation (EC) No 552/2009, Official Journal of the European Union, L 164/17

[2] RoHS, Directive 2002/95/EC of the european parliament and of the council, Official Journal of the European Union, L 37/19

[3] S. Lu, I. Hamerton, Prog. Polym. Sci, 27, 2002, 1661-1712

[4] B. Schartel, Materials, 3, 2010, 4710-4745

[5] U. Braun, A. I. Balabanovich, B. Schartel, U. Knoll, J. Artner ,M. Ciesielski, M.Döring, R. Perez, J.K.W. Sandler, V. Altstädt, T. Hoffmann, D. Pospiech, Polymer, 47, 2006, 8495-8508

[6] R.E. Alcock, J. Busby, Risk Analysis, 26 (2), 2006

[7] B.R. Wang, L. Tan, Sichuan Ligong Xueyuan Xuebao, Ziran Kexueban. 23(5), 2010, 524-526

[8] C. Negrell-Guirao, B. Boutevin, G. David, A. Fruchier, R. Sonnier, J-M. Lopez-Cuesta. Polym. Chem., 2, 2011, 236-243

[9] Q.Lv , J. Huang, M. Chen, Z. Jing, T.Yi, C. Li, W. Yu-Zhong. Industrial and Engineering Chemistry Research 2013

[10] D. Kyrioacos, GEM-chem ; ISBN: 9789078546269,2012

[11] G.Lligadas, J.C. Ronda, M.Galià, V. Cadiz, Journal of Polymer Science : Part A : Polymer Chemistry, 44, 2006, 5630-5644

[12] H. Ren, J. Sun, B. Wu, Q. Zhou. Polymer degradation and stability, 92, 2007, 956-961

[13] R.M. Perez, J.K.W. Sandler, T. Hoffman, J. Ârtner, A.I. Balabanovich, U.Knoll,U. Braun, B, Schartel. Journal of Applied Polymer Science, 105, 2007, 2744,2759

[14] D. Neugebauer, K.Bury, M. Wlazlo, Journal of Applied Polymer Science, 124, 2012, 2209-2215

[15] Y.Iwakura, T. Kurosaki, N.Ariga, T. Ito. Die Makromolekulare Chemie, 97, 1966, 128-138

[16] M. S. Gluckman, M. J. Kampf, J.L. O’Brien, T.G. Fox, and R.K. Graham, J.Polymer Sci, 37, 1959, 411.

[17] Zhor El-Asri, "Synthèse par polymérisation radicalaire de nouveaux additifs phosphonés incorporés dans un revêtement à base de PVDF pour la protection de surface métallique.", PhD thesis in materials chemistry, direction : Bernard Boutevin, Montpellier, UMII, 2007.

[18] C. Huggett, Fire Mater. 4, 1980, 61-65

[19] C. Loubat, B. Boutevin, Macromol. Chem. Phys, , 2000, 2853-2860

[20] C. Boyer, G. Boutevin, J.J. Robin, B. Boutevin. Polymer, 45 (23), 2004, 7863-7876

[21] C. Loubat, S. Soulier, B. Boutevin, Polymer Bulletin 45, 2011, 487-494

[22] C. Boyer, G. Boutevin, J.J. Robin, B. Boutevin. Macromolecular Chemistry and Physics, 205 (5), 2004, 645-655

[23] H. Vahabi, L. Ferry, C. Longuet, R. Sonnier, C. Negrell-Guirao, G. David, J.M. Lopez-Cuesta, European Polymer Journal, 48, 2012, 604-612

[24] R. Auvergne, S. Caillol, G. David, B. Boutevin, J.P. Pascault, Chemical Reviews, 114(2), 2014, 1082-1115

[25] L. Gonzalez, F. Ferrando, X. Ramis, J.M. Salla, A. Mantecon, A.Serra Progress in Organic Coatings, 65(2), 2009, 175-181

[26] M. Bertoncini, J.C. Hoepfner, S.H. Pezzin, Current Organic Chemistry 17(17), 2013, 1838-1843

[27] S.V. Levchik and E.D.Weil, Polym. Int., 54. 2005, 11-35

[28] D. Price, L.K. Cunliffe, K.J. Bullett, T.T. Hull, G.J. Milnes, J.R. Ebdon, B.J. Hunt, P. Joseph. Polymer Degradation and Stability, 92, 2007, 1101-1114

[29] L. Tibiletti, L. Ferry, C. Longuet, A.Mas, JJ.Robin, JM.Lopez Cuesta, Polymer Dgradation and Stability, 97 2012, 2602-2610

[30] R.M. Perez, J.K.W. Sandler, T. Hoffman, J. Ârtner, A.I. Balabanovich, U.Knoll,U. Braun, B, Schartel. Journal of Applied Polymer Science, 105, 2007, 2744-2759

[31] F. Laoutid, L. Bonnaud, M. Alexandre, J. M . Lopez-Cuesta, P. Dubois, Mater. Sci. Eng., 63, 2009, 100-125 


\section{Tables of Captions}

Table 1: Amounts of monomers introduced in copolymerization

Table 2: Compositions of the formulated epoxy materials

Table 3: Radical chain transfer copolymerization of MAGLY with MAPC1

Table 4: PCFC data

Scheme 1: Radical chain transfer polymerization of Glycidyl methacrylate (MAGLY) with Dimethoxyphosphorylmethylmethacrylate (MAPC1) in presence of mercaptoethanol

Figure 1: ${ }^{1} \mathrm{H}-\mathrm{NMR}\left(\mathrm{CDCl}_{3}\right)$ of $20 \mathrm{EP} 80 \mathrm{P}$ oligomer

Figure 2: TGA thermograms of oligomers 100EP, 70EP30P, 50EP50P, 20EP80P, 100P under nitrogen atmosphere at $10^{\circ} \mathrm{C} / \mathrm{min}$

Figure 3: a) Diglycidylether Bisphenol A (DGEBA), b) Isophorone diamine (IPDA)

Figure 4: DSC analyses of 100EP/IPDA and DGEBA/IPDA systems operated at $10^{\circ} \mathrm{C} / \mathrm{min}$

Figure 5: (a) Cross-section of the material 2.1\%P (20EP80P), (b) Cross-section of the material 3\%P(100P)

Figure 6: DSC analyses $\left(10^{\circ} \mathrm{C} / \mathrm{min}\right)$ of the materials

Figure 7: TGA curves of reference, O\%P(100EP), $2.1 \% P(70 E P 30 P), 3 \% P(20 E P 80 P)$ materials under nitrogen atmosphere at $10^{\circ} \mathrm{C} / \mathrm{min}$

Figure 8: DTG curves of reference, $0 \% P(100 E P), 1 \% P(70 E P 30 P), 3 \% P(20 E P 80 P)$ materials under nitrogen atmosphere at $10{ }^{\circ} \mathrm{C} / \mathrm{min}$

Figure 9: Evolution of $\mathrm{T}_{10}$ (a) and char content (b) versus initial phosphorus content of all materials

Figure 10: PCFC curves of the reference, $0 \% P(100 E P), 0.8 \% P(70 E P 30 P), 0.9 \% P(50 E P 50 P), 1 \% P(20 E P 80 P)$ materials

Figure 11: PCFC curves of the reference, $0 \% P(100 E P), 0.9 \% P(70 E P 30 P), 1.35 \% P(50 E P 50 P), 2.1 \% P(20 E P 80 P)$, $3.0 \% P(20 E P 80 P)$ materials

Figure 12: PCFC curves of the reference, $3 \% P(20 E P 80 P)$ et $3 \% P(100 P)$ materials

Figure 13: Evolution of THR (a), EHC (b) and pHRR (c) versus initial phosphorus content of all materials 


\section{Graphical abstract}
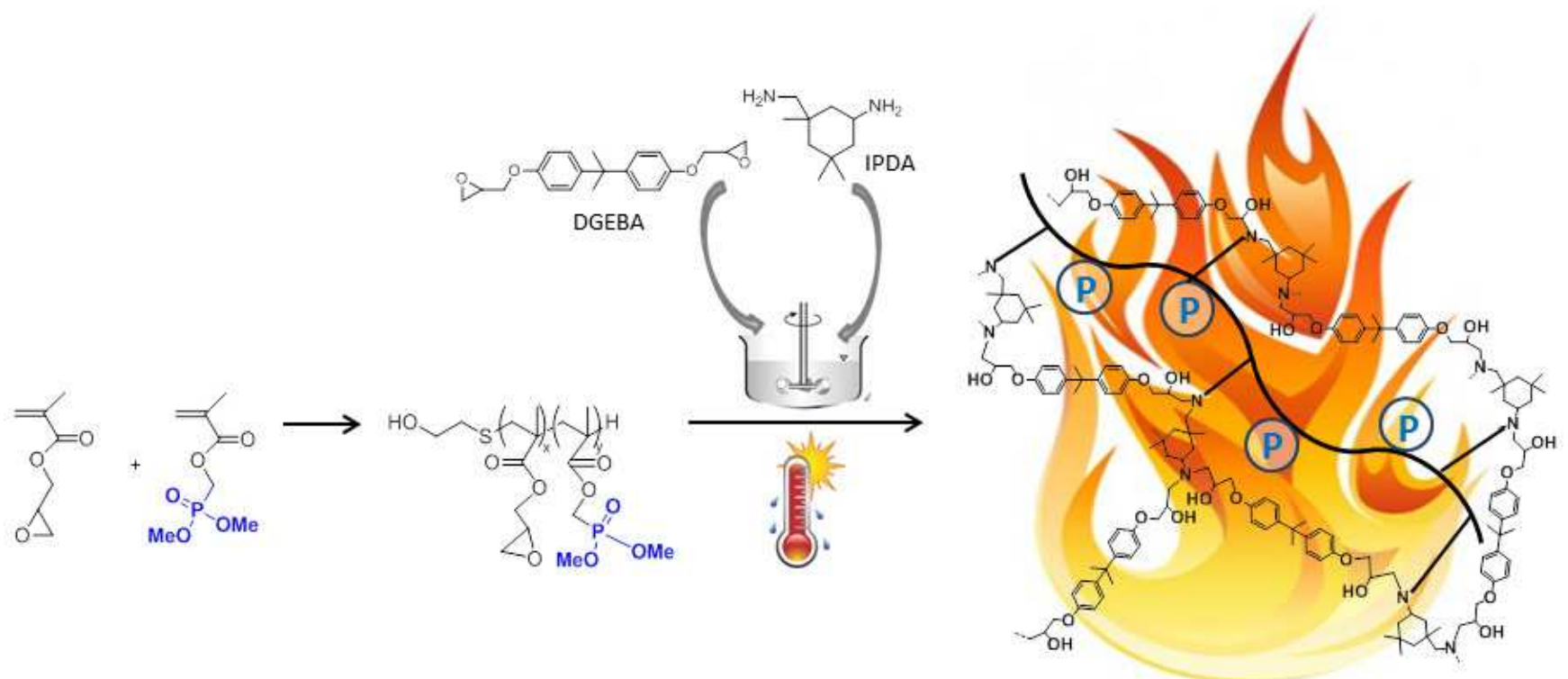

\section{Highlights}

1. Synthesis of original reactive phosphorus-containing oligomers

2. Comparative study of reactivities of glycidyl methacrylate with dimethoxy-phosphorylmethyl methacrylate

3. Covalent grafting of flame retardants in epoxy network

4. Assessment of flame retardant properties 